\title{
A morphological history of urban centers in Qingdao
}

\author{
Haofeng Wang ${ }^{*}$ (iD and Xiaojun Rao
}

\begin{abstract}
This study applies space syntax methodology and investigates the centrality process of four centers in Qingdao, China, which grow from old settlements during successive phases of urban growth. The aim is to increase the understanding of how urban form can generate and sustain centers as well as embed them in, or distinguish them from their context that has been built up in a rather complex geographic region. Results reveal the development of these centers and the associated different scales of accessibility are related to both pre-urban road network of the city and the local grid conditions of those settlements from which a center has grown. The overall condition of the city frames the global structure of the city and renders those settlements with potentials for movement-engaged activities. The local grid structure set by metric and topo-geometric properties influences the actual concentration patterns of social economic activities and determines the range and strength of a center in the city. The study suggests that the morphological structure of the city may be historical in nature, in the sense that old settlements are not simply "absorbed" by urban growth, but can sustain or even function as a center given proper spatial environment.
\end{abstract}

Keywords: Morphology, Local grid condition, Qingdao, Urban center

\section{Introduction}

Rapid urban growth in modern cities is often associated with suburban development, with the built-up areas of city expanding into their surrounding environment and assimilating many edge settlements and towns through successive phases of development (Fig. 1). As cities grew in size, their urban areas varied not only in functional differentiation, i.e., concentration of socio-economic activity and distribution of land use, but also in terms of morphological feature, i.e., the physical and spatial patterns characteristic of a given built area (Siksna, 1997). Meanwhile, urban growth often led to an evolution of urban centers with old ones decaying or even ceasing to function and new centers or sub-centers being created. In this sense, an urban structure generally contains the functional aspects representing the interactions between form and function, which in turn illustrate the spatial

\footnotetext{
* Correspondence: whf@szu.edu.cn

School of Architecture \& Urban Planning, Shenzhen University, No. 3688 Nanhai Ave. Nanshan District, Shenzhen 518060, China
}

conditions facilitating the morphological agglomeration of land uses. Revealing the links between the spatial and functional elements of the urbanization process is vital for any urban renewal project, as it contributes to sustaining the long-term prosperity of urban centers (Burger \& Meijers, 2012; Tallon, 2013).

The question about urban centers draws attention to the notion of centrality. Depending on the context of discussion, the term of centrality has different implications (Cutini, 2001; Hillier, 1999). For example, the architectural perspective generally tackles the issue of centrality with the morphological properties of centers. The regional planning approaches it from the functional aspects by taking into account land use attractiveness, intensity of populations and functions located in particular areas. However, neither is sufficient to answer the question about the reasons influencing the primary locations of centers and activities in a center. It remains unclear why a place is central, and whether land use aspects of a center are independent of space or not, or there are underlying spatial processes driving the development of centers in specific 


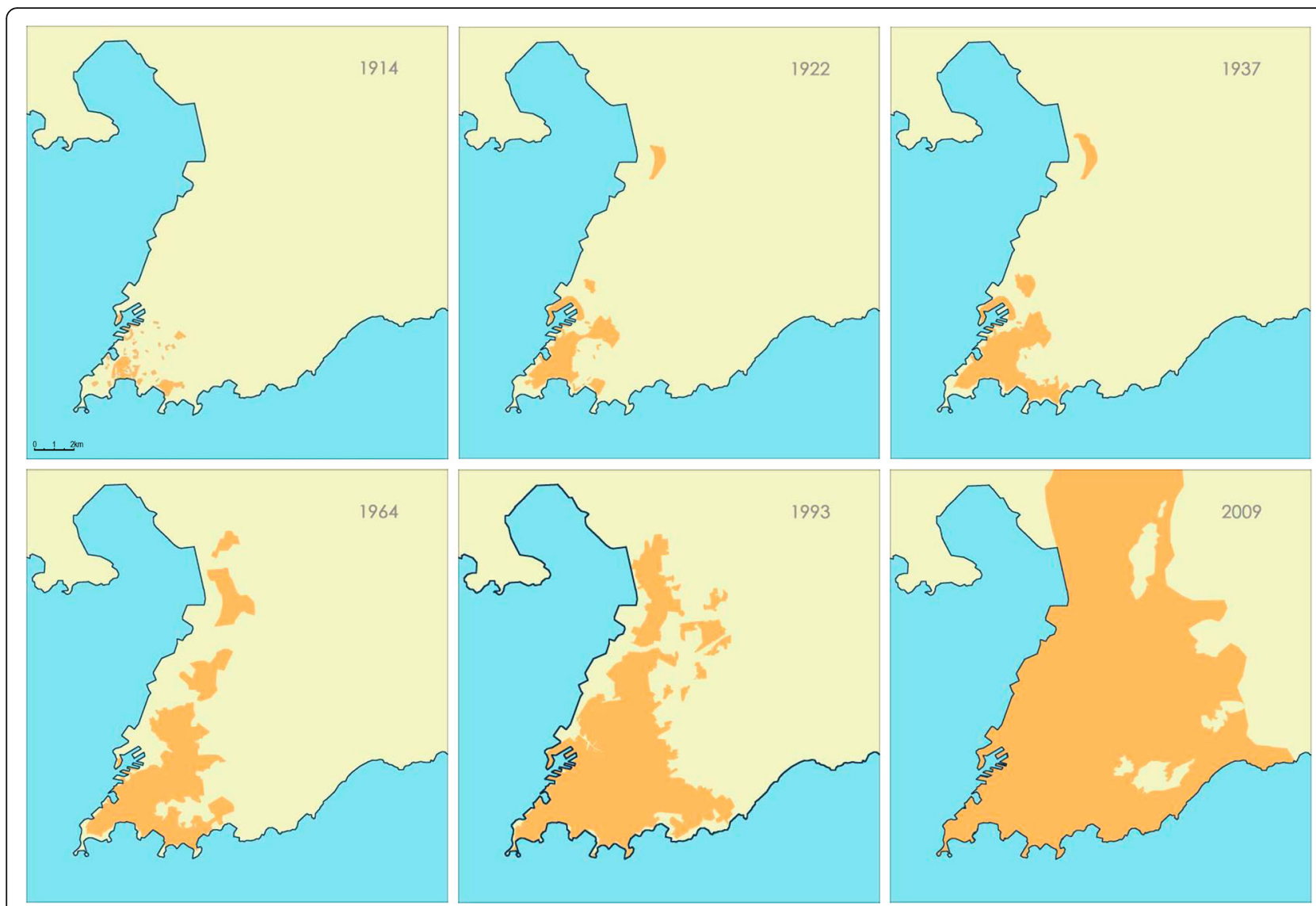

Fig. 1 Growth and expansion of the built-up area of Qingdao from 1910 to 2010s (Shanghai Tongji Urban Planning and Design Institute; Qingdao City Planning and Design Institute, 2014)

directions rather than merely as responses to economic and planning decisions.

Although the space and function relationship of city has been a major issue of urban research for decades, it is not until Hillier who had theorized a general linkage between them via the mechanism of systematic influence of spatial structure on movement distribution (Hillier et al., 1993), and through this to influence the location choice of land use (Hillier, 1996). With their emphasis on the structural properties of spatial configurations, syntactic studies focus on the formulation and reproduction of hierarchical urban centers as driven by theories of movement economy and centrality process, upon which the spatial interactions of spatial elements occur at various scales in a city (Hillier, 1999). The land use patterns identified by syntactic studies are considered as the products of spatial centrality generated by the urban grid. Many studies have demonstrated the vital role of spatial centrality on the distributed patterns of commercial land uses (Hillier, 1999; Peponis et al., 1997; Porta et al., 2009; 2012; Scoppa \& Peponis, 2015).

The comparative study of urban form through time facilitated by space syntax research has open up possibilities for exploring the relationship between urban transformations and social activities from the perspective of urban history. However, studies in this field have predominately been done for European and American cities. Those carried out in the Chinese context remain relatively few, and most of them focus on cases extending continuously from a single historical core without much geographical constraints (Dai \& Dong, 2005; Feng et al., 2012; Shen et al., 2013; Wang et al., 2008; 2017).

This paper represents a continuation of space syntax in the Chinese context and tends to fill the gap by examining the centrality process of geographically complex cities. The specific case selected is the city of Qingdao whose historical urban area was originated in the late nineteenth century as a German colonial city, and grew from discrete zoning quarters scattered around a hilly topography along the coast of Shandong province, eastern China. Particular attention is given to the development of four centers and sub-centers growing up from settlements or pre-urban towns that had been built through successive phases of urban growth before the 1950s. For about a century, continuous urban developments implemented by different administrations have 
gradually merged those discrete quarters into a large urban whole with dramatic urban transformations that turned those old areas into centers and sub-centers with varied socio-economic concentrations. Not only has the organization of city space been largely constrained by the complex geographical conditions of Qingdao, but its spatial arrangement has presented divergent urban planning traditions as well. All of these seem to have contributed to the distinct patchwork-like spatial pattern of Qingdao today.

From s historical point of view, the processes of urban growth of Qingdao present peculiarities in their regional context that demand more in-depth investigations in order to understand how its centers spatially, functionally and economically evolve. What is the impact of urban growth on the centrality and creation of centers? If urbanization does not mean to an end of the old, then what does the urban past contribute to the sustaining or the creating of their present conditions?

The study hypothesizes that the development and evolution of centers in Qingdao can be accounted by the emergent centralities imposed by cross city accessibility on the divergent regional quarters. To test the research hypothesis, the configurational analysis of space syntax is conducted and the morphological variations of centers are described and classified in relation to the city's urban past. By analyzing the relationship between the spatial characteristics and the functional roles of centers, the aim is to increase the understanding of how urban form can generate and sustain centers as well as embed them in, or distinguish them from their context that has been built up in a rather complex geographic region.

\section{Data and methods}

The study area is the site that has been declared as the historical city of Qingdao by the local authorities. It covers an area size about $28 \mathrm{~km}^{2}$ (Fig. 2). Data used in this study consist of two sets: spatial variables and land use data. Spatial variables are derived by the configurational analysis of space syntax on the linear structure of street system at different scales. The spatial analysis model is built upon an official digital city map (in Autocad format, scale 1:1000) by courtesy of Qingdao City Planning and Design Institute. Contemporary land use data of the centers and sub-centers of interest are collected by graduate students at the School of Architecture \& Urban Planning Shenzhen University. Historical maps and data are obtained from the open-access online map resources (Digitized Resources of the Library of Christian-Albrechts University Kiel, 2018) and previous studies on the city building history of Qingdao (Qingdao Municipal Archives, 2002).

Space syntax methodology is applied to investigate whether the emergence of centers and sub-centers of Qingdao is related to their local grid conditions and their global connections with the city, and whether this has a historical relevance with the different levels of spatial accessibility associated with distinctive phases of urban development. The particular tool we use to analyze the morphological properties of Qingdao is the

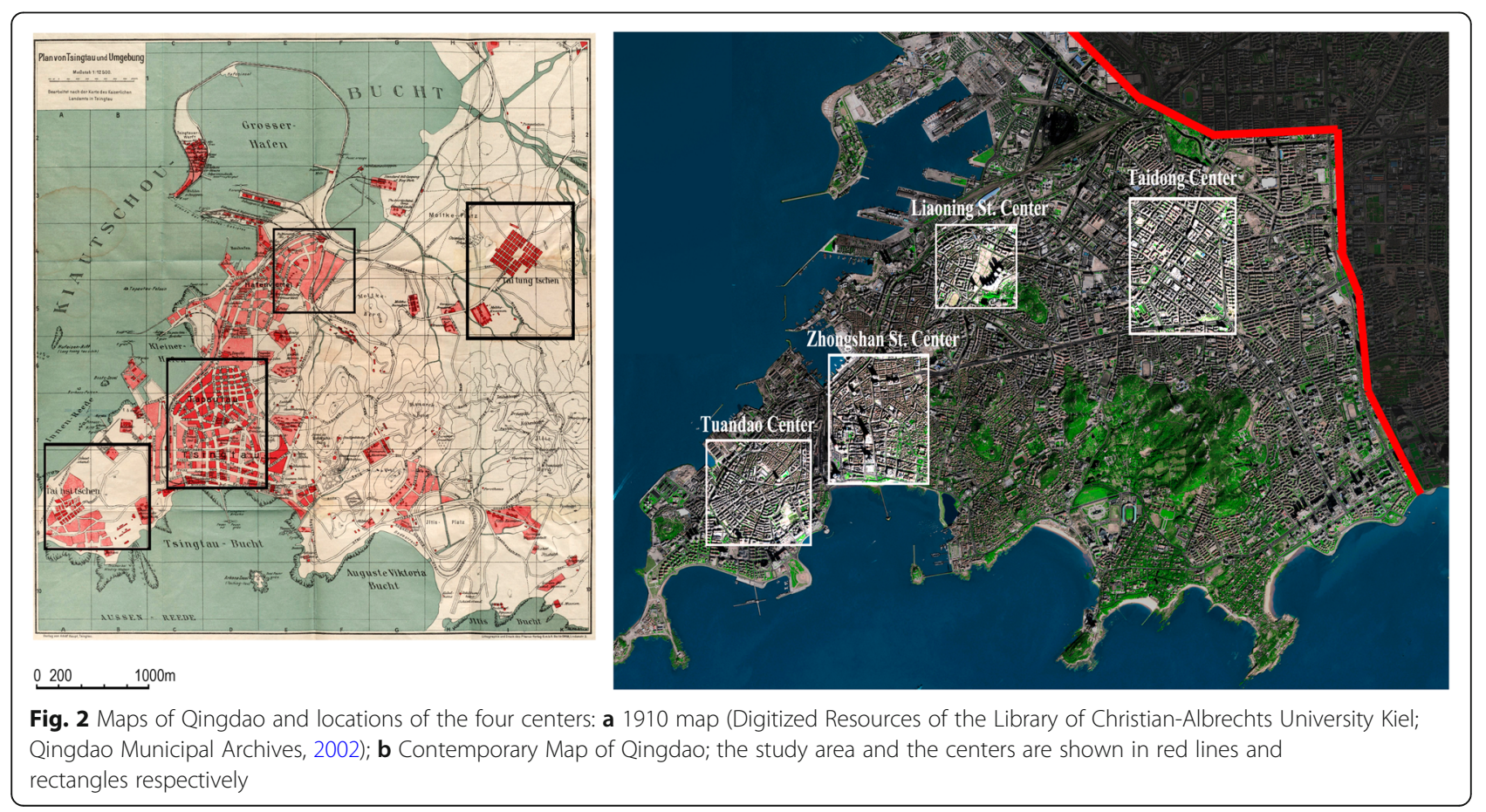


classical space syntax computer program "Depthmap" developed by Turner at University College London (Turner, 2004). Both the axial and the segment modeling techniques of space syntax are used in this study. Detailed explanations of the methodological concept and quantitative measures of the modeling techniques can be found in the classical space syntax literature (Hillier \& Hanson, 1984; Hillier \& Iida, 2005) and recent publications (Al-Sayed et al., 2014; van Nes, 2021; Yamu et al., 2021).

The input data of "Depthmap" are the axial lines and their constituent segments. The axial model is the linear representation of a city's street system. It models the street system as a minimum set of the longest possible lines of movement that are inter-connected each other. Although the axial model can be constructed automatically from a street boundary map by the computer algorithm of "Depthmap" (Turner et al., 2005), drawing the street boundary map with due details of a large urban area is not an easy task and quite time consuming. In this study, the axial map of Qingdao is drawn manually. It starts by intuitively drawing the longest possible lines along streets and then the second longest lines until all streets are covered by inter-connected lines without any redundancy of connection. The connectedness of such axial lines can be quantified by measuring each line's spatial position with respect to other lines in the system. The simplest variable is connectivity, which is the number of axial lines that are directly connected to an axial unit. However, the inter-connections within a street system are far more complex than this. Some streets are more accessible than others and thus have greater potential as destinations to attract to-movement flows, others streets are more likely to be traversed as the shortest path between a pair of streets and thus have greater potential in terms of through-movement flows. Space syntax analyzes these movement potentials with two measures. The integration measure describes the "closeness" of an axial line in terms of the number of topological turns (or steps) to move from that line to all other lines, and thus shows the to-movement potentials. The greater the number of topological turns between axial lines, the lower the integration value. Conversely, the lower the number of topological turns to all other axial lines, the higher the integration. The choice measure is similar to the "betweenness" property of network analysis. It measures the accumulative opportunities of each axial line traversed by all short paths generated by every line as both origins and destinations, and thus shows the through-movement potentials. Both the integration and choice calculations can be applied by using a topological radius cut. For example, radius 3 (R3) Integration measures the degree of relative accessibility of a space with respect to its surrounding spaces no more than 3 topological steps from it, and therefore indicates the local structure of a street system. Whereas Rn (unlimited radius) integration is the most popular measure to represent the global structure of a system in space syntax literature. Those outer streets will suffer from the "edge effect" in integration computation. Such "edge effect" can be somehow remedied by analyzing the radiusradius ( $R r)$ integration. It simply takes the number of mean steps of the highest integration street within a system as the radius limit in integration calculation, and is a preferred global measure when comparing the subsets of space across different areas.

The segment model of space syntax is a derivation from the axial model. It breaks up the axial lines at their intersections and takes every segment between line intersections rather than the whole line as the basic analytical unit. This makes it possible to compute a finer grain of the linear structure of streets by taking into account angular weighting and metric properties between segments. Instead of taking the least number of topological turns as the cost of distance, the segment model measures distance in terms of accumulated angular deviation between a pair of segments (Hillier \& Iida, 2005). Figure 3 shows the differences of graph representation between the axial model and the disaggregated segment model. The resulting measures that describe the tomovement and through-movement potentials of the segment model are angular integration and angular choice. By setting the segment analysis at various metric radius, the finetuned angular analysis allows research to assess how integrated a street segment is within a local catchment area. Such practices are widely used by space syntax research to analyze the multi-scale structures of cities that are characterized with a centrality process of spatial integration and movement related land use distributions. In particular, local integration or choice analyzed at a small metric radius between 400 and $1500 \mathrm{~m}$ (5-20 min walking distance) are generally found to correlate strongly with pedestrian flows and retail locations, while these measures at a large metric radius of $3000 \mathrm{~m}$ and beyond are more strongly associated with vehicular traffics (Chiaradia et al., 2012; Hillier, 2009 \& 2016; Ozbil et al., 2011; Sheng \& Zhou, 2018; Yamu \& Frankhauser, 2015).

Historical maps and contemporary maps of Qingdao are compared based on the syntactic structures analyzed with both axial and segment models. Land use distribution and the location pattern of retails of the study area are registered manually. The purpose is to see how the four centers and sub-centers of the city located themselves and developed with respect to the changing spatial accessibility due to urban growth and expansion. While the axial model is mainly used to analyze the part and whole relationship of urban areas in a general sense, the 


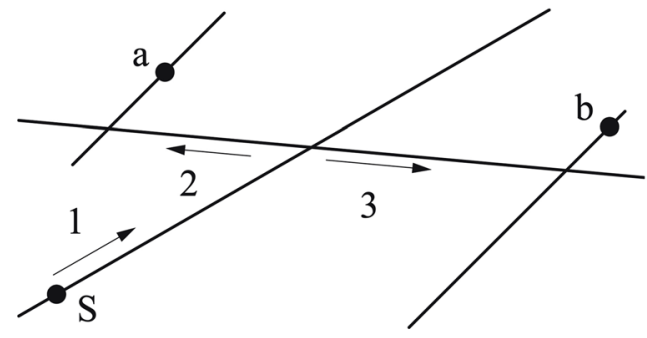

(a) line model

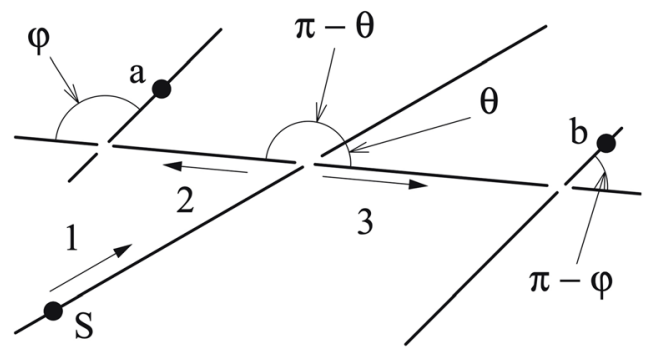

(c) segment model

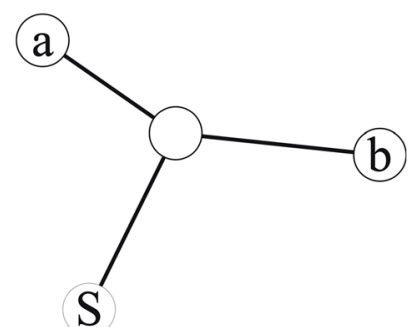

(b) graph of (a)

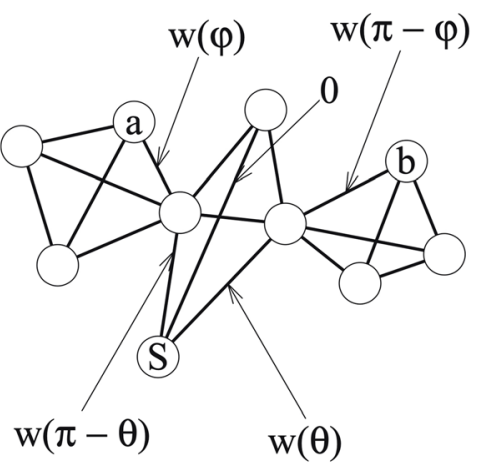

(d) graph of (c)

Fig. 3 Maps showing the differences between the axial model (a) \& (b), and the segment model (c) \& (d) (Hillier \& lida, 2005)

segment model allows a more detailed investigation of configurational variations of the linear structure at a given metric scale, thus providing a precise understanding of how centers are embedded in the street network.

Spatial variables of each urban area are extracted to see if centers are configurationally different from each other and from their urban context. Retail distribution of each center is then mapped and compared to see whether the spatial difference between the centers and sub-centers could explain their retail development variation as well as their functional differentiation.

\section{The four urban centers in the old city of Qingdao: a historical review}

The four centers and sub-centers located in the historical urban area of Qingdao took their shapes before the 1950s (Li \& Li, 2005; Warner, 2011). Built forms of this area followed largely the planning scheme developed by Germany colonists who occupied Qingdao under Jiaozhou Bay Concession in 1898 (Fig. 4). The German plan of Qingdao was based on a zoning of land use function and social classification. By the end of German reign in 1914, two urban areas were established: the European district located in the south, which included administrative, office and residential facilities for western people; and the Chinese town for local tradesmen and office staff (Li, 2007; Li \& Zhou, 2007). These two districts constitute the core of Qingdao's historical area.
The extent of change and continuity of the four centers and sub-centers is illustrated in Fig. 5, which shows contemporary main streets overlaid on the historical map of 1910. The Zhongshan Street Center is located in the core of Qingdao's historical area. As the oldest commercial center of Qingdao, its origin could be dated back to the period of German occupation. The center is named after Zhongshan Street, the central axis of the historical core of Qingdao. The importance of this street could be easily explained in terms of its historical significance as a strategic linkage of the city, as indicated by the concentration of commercial and institutional buildings during the first half of the twentieth century (Fig. 6). While initially focusing on Zhongshan Street, this center today expands itself much in size toward the east, transforming many of the residential buildings in the old Chinese town into retail facilities. In spite of the functional transformation, the deformed grid structure of the urban fabric has been largely preserved, offering the center a characteristic layout pattern.

In contrast to the Zhongshan Street Center, the present street network in the other three centers is largely pre-urban in nature. In some cases, the historical map shows how the contemporary streets cut across historical field boundaries, indicative of more recent intervention, but more often they follow older lines. The Liaoning Street Center is situated to the north of Qingdao's historical core. The area was built in the 1920s as a 


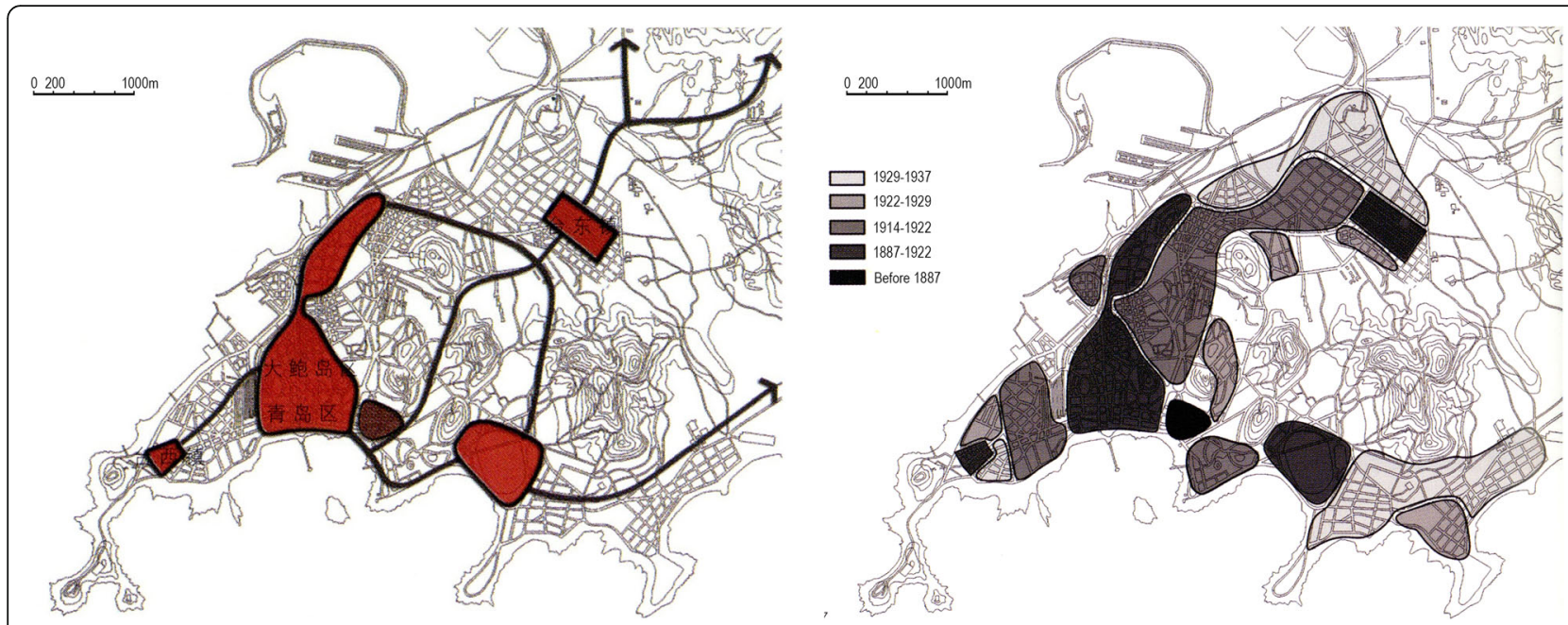

Fig. 4 The early stage of urban expansion in Qingdao before the 1940s: a red color showing the built up areas by 1914 ; b the successive phases of development from the 1900s to 1930s, the darker the color the earlier the development $(\mathrm{Li}, 2007)$

settlement for Japanese immigrants. The settlement was originally sited at the junction of the east by-pass and the road leading southeast out of the port area. It then grew towards the north with the coming development of port areas since the 1930s. It seems that the topographic features also had an impact on the street pattern of this area, as indicated by the curvature shape of streets. These streets either followed the contour of the land or were aligned with the port areas, forming a deformed grid pattern with strong radial lines and thus giving the Liaoning Street Center a distinct character of physical form. The current main shopping street runs along the line of the pre-urban road, i.e., the western segment of contemporary Liaoning Street. This history suggests that it is not sufficient to consider the emergence of this subcenter without addressing the impact of the structure of road network on the structuring of space.

The Taidong Center developed from a settlement, which was established by the German to reallocate local fishermen whose residence was swept out during Qingdao's early urbanization period. The settlement was located in the eastern suburban area of the old Qingdao city, where roads leading out of the city met each other. The identity of Taidong as a populace center derives from the 1920s when the old settlement was turned into a town to accommodate industrial workers. The areal size of the town was expanded significantly in the 1930s. After the 1950s the town shifted towards the south with the coming development associated with urban growth. Unlike other urban areas that were built on a more or less hilly topography, the rather flat land feature around Taidong allowed the settlement to be planned in orthogonal grids with high street density. The expansion of the settlement also followed the rule of orthogonal configuration, although going into a larger block structure.
Today Taidong is the largest living center in the historical area of Qingdao, with a significant concentration of large retails and a mixture of diverse commercial activities. Retails were distributed in this area in a more or less linear manner in the past, but now they are concentrated in a convex pattern. It seems that the large areal size and the higher street density of the Taidong Center are relevant to the change of its retail distribution pattern. This indicates that the emergence and development of the center are rather recent intervention of its historical road network.

The Tuandao Center lies on a hilly ground in the west of Qingdao. It also developed at the junction of roads leading out of the city, and was once a lower-class settlement for impoverished people. Being separated from the city by the railway line, it developed a rather closed spatial system with a series of circular streets punctured by radial lines from outside, giving a distinct physical form of the settlement. It is clear that the development of the settlement had been greatly affected by the expansion of port areas and the development of the railway suburban. However, the emergence of this sub-center and the location of its main shopping street could not be better understood without addressing its strategic location choice on the intersection of suburban growth axes.

To sum up, the overlapping of the contemporary street network with the historical map for the centers and subcenters illustrates how their forms are influenced by those constraints associated with suburban or fringe area development, such as the structure of historical road network and topographic feature. Those constraints have an impact on the emergence of the four centers not only by differentiating their internal configuration, but also offering centers with distinctive characters in terms of the ways that a center is connected with the city. Each 


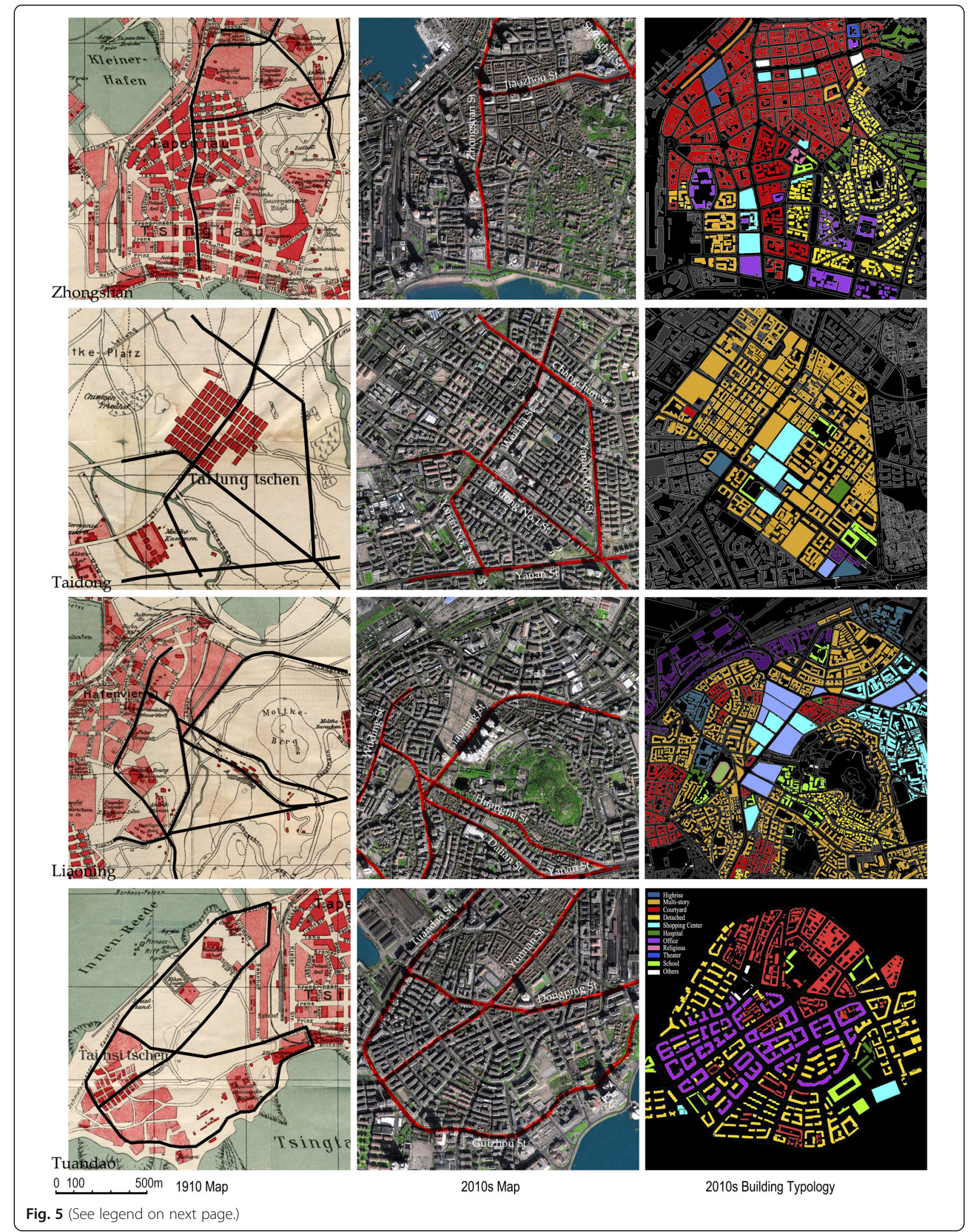


(See figure on previous page.)

Fig. 5 Maps showing the four center areas of Zhongshan, Taidong, Liaoning and Tuandao (from top to bottom) in 1910 (left column), $2010 \mathrm{~s}$ (middle column) and building types in 2010s (right column)

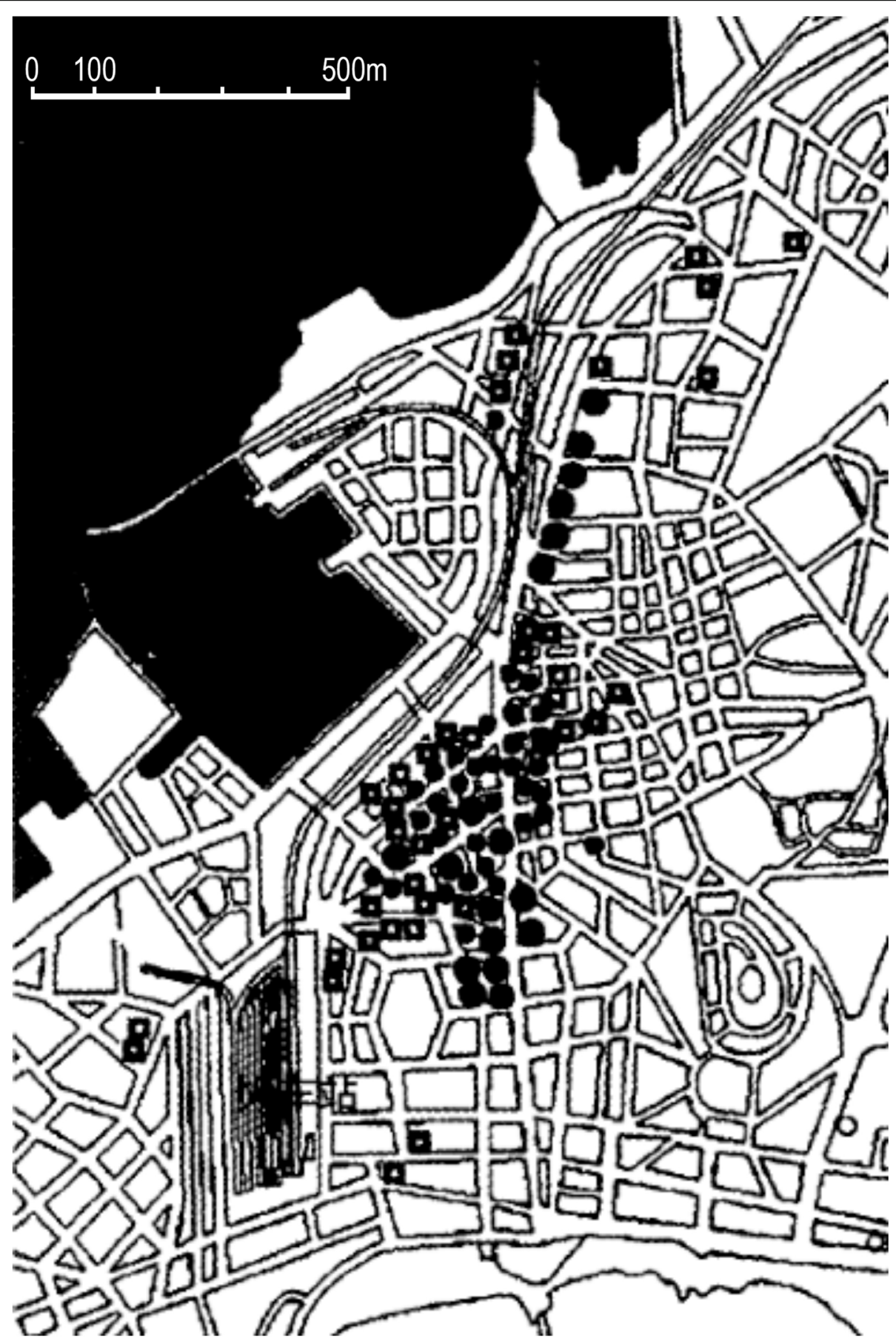

Fig. 6 Concentration of major commercial buildings and banks (shown in box and circle) along Zhongshan Street in 1937 (Li \& Zhou, 2007) 
center appears to be different, reflecting the particular history of its origin and development. For instance, the topographic constraint clearly has less impact on the spatial form of the Taidong Center than the Liaoning Street Center and the Tuandao Center. While the shopping street of the Liaoning Street Center is mainly aligned with the line of a pre-existing road, the socioeconomic activities in the Taidong Center tend to be influenced by more recent urban growth after the 1950s.

\section{Results}

\subsection{Spatial profile of centers}

The axial organization of Qingdao displays characteristic areal variations of local geometry due to its hilly topography. Longer lines tend to be distributed into clusters, which is particularly prominent when an area takes the orthogonal grid structure. However, linear continuity of long lines could still be observed. The linearity is mainly formed by major streets between local areas, although it focuses on a less global level than other organic cities. Moreover, a comparison of the axial organization and the macro-level land use map of the city could provide a preliminary understanding of the spatial differences between land use types. For urban centers whose land use is primarily for commercial and office, axial lines are often organized in a more or less orthogonal grid pattern with denser and smaller islands. In the south part of the city where land use types are mainly institutional and administrative, the axial lines are configured with a larger-scale of block structure, although they may also take an orthogonal configuration. Another observation of the syntactic structure is the spatial difference between traditional street-based settlement and modern estate-based development. Whereas the former has an axial configuration similar to that of institutional and administrative blocks, the latter takes the structure of sparse grids containing very large blocks with fewer islands and broken axial organization.

The integration structure (angular Int-Rn) of Qingdao is strongly biased toward the north, leaving the south as rather segregated spaces (Fig. 7). Although the integration core (consisting of lines with high integration values and shown in red color) takes a deformed wheel structure, it has a very strong spoke leading towards the east along Yan'an Street. When this spoke meets the main streets in the east (Yan'an No. 1 street and No. 3 street), it develops a new core with strong radial lines. The integration structure of Qingdao tends to indicate that the city has a configuration of multiple centers. One is located at the historical core of the city, and the other is formed around Taidong (Fig. 7). The local integration (angular Int-R750m) map reveals that spatial centrality is focused on four areas. It turns out that these areas are either the centers or the sub-centers that are examined in this study (Fig. 8). Meanwhile, the historical core of the city has a much stronger integration structure than the other three areas, both locally and globally.

Tables $1 \& 2$ tabulate both geometric and syntactic values of the analyzed axial structure. As shown, the four centers perform better in almost every aspect than the city as whole. Geometrically, these centers are comprised by longer axial lines with more segments, as manifested by their lower values of segment length to line length ratio. On the other hand, although the centers have higher

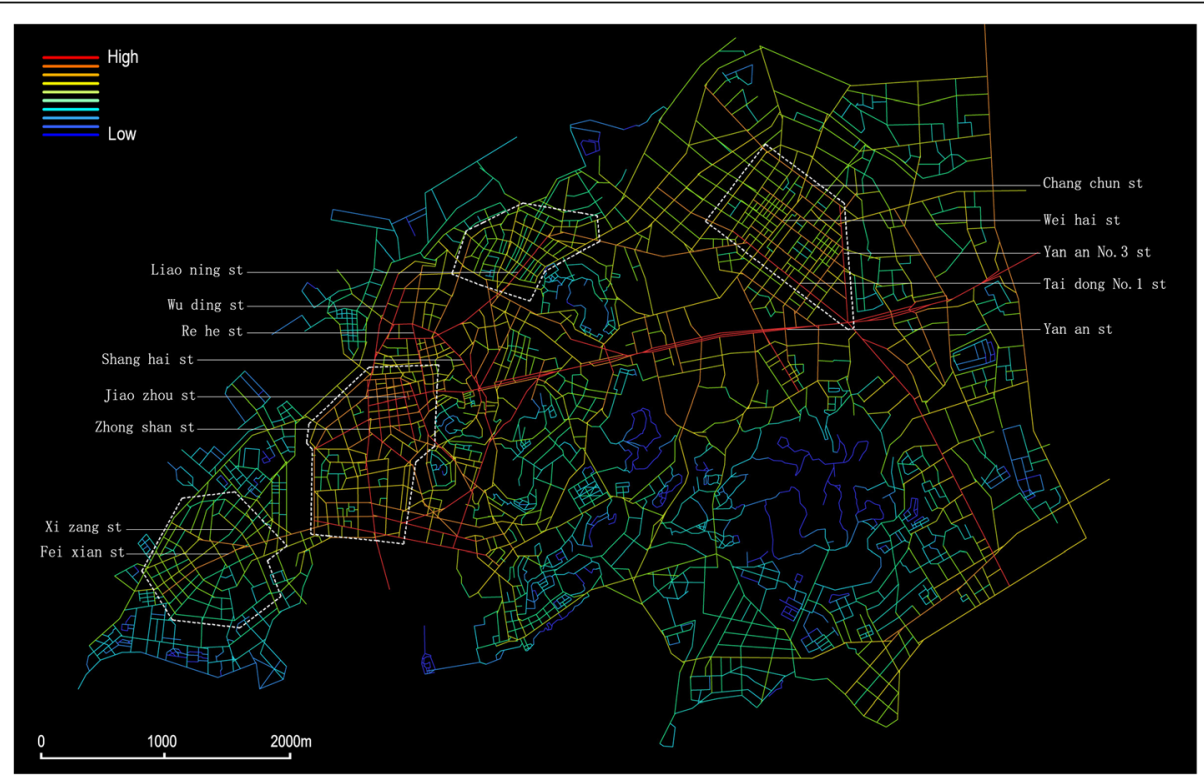

Fig. 7 Global angular integration of Qingdao, red-blue gradient showing high-low values 


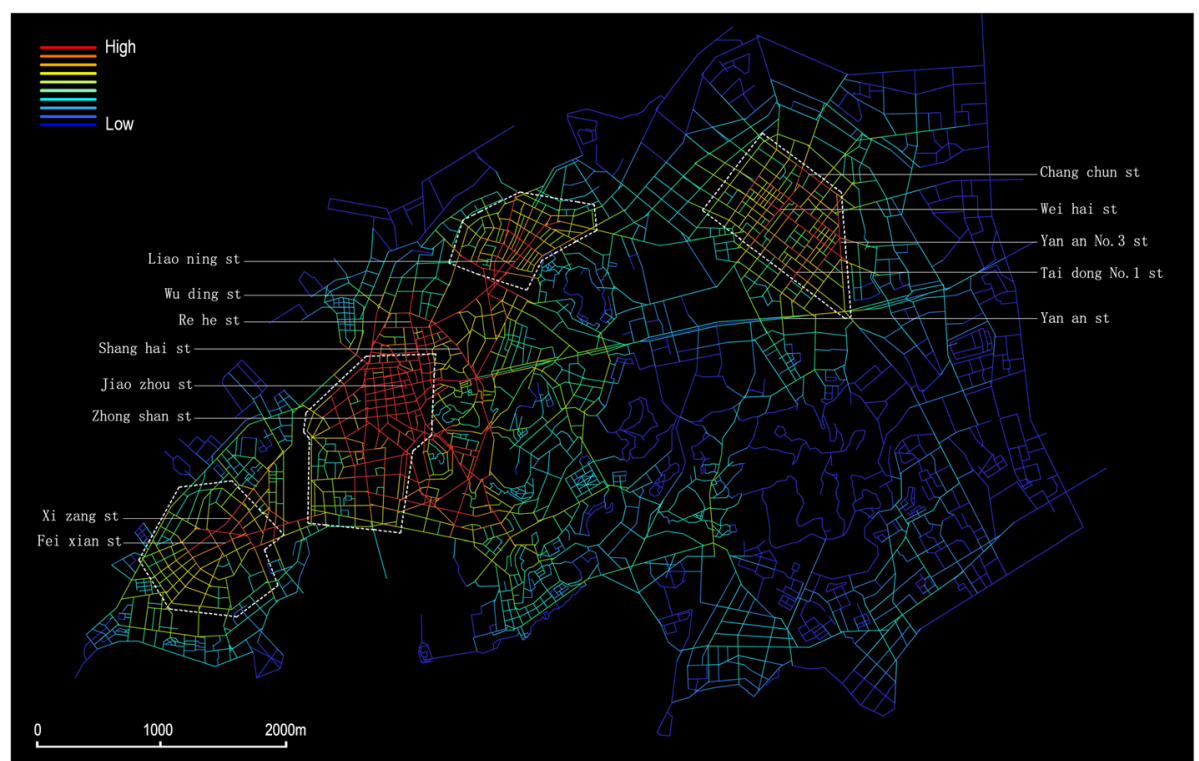

Fig. 8 Local (R750m) angular integration of Qingdao, red-blue gradient showing high-low values

values than the city as a whole both in terms of local and global syntactic properties, the difference appears to be more pronounced at the local level, as indicated by the higher connectivity and integration values of the centers at a low radius. In other words, the centers consistently have a more orthogonal and integrated grid structure that is composed by denser streets and smaller blocks, whereas the rest of the city and especially the residential areas developed recently are likely to have a more broken and segregated integration structure that is made up of larger blocks and fewer islands.

Moreover, syntactic analysis also reveals that the centers and sub-centers are more metrically integrated. This analysis is conducted by computing the average metric distance from each street segment to all other segments within a radius of $1500 \mathrm{~m}$. The result is visualized in Fig. 9, which shows the different shapes of urban areas with "natural spatial area-isation" (Hillier et al., 2007) highlighted as blue patchworks. It clearly picks out the four centers and sub-centers, which are all connected by capital routes with high global integration values. Given that those localities are relatively self-similar and maintain higher intelligibility, the boundaries of the patchworks thus represent the interface between the vicinities and the context (Park, 2009; Yang \& Hillier, 2007 \& 2015). This means that, at a walkable range $(1500 \mathrm{~m}$ equal to $20 \mathrm{~min}$ walking), distance between streets in a center is less than in other urban areas, allowing an ease for pedestrian trip to distribute the city scale accessibility in an effective way to capitalize movement engaged land use such as retails.

Even within a center, a subtle spatial variation between different types of land use could be discerned. For example, in the Zhongshan Street Center, street blocks containing office buildings in the south have a larger block size and a lower local integration value than street blocks containing retail shops in the north. The former appears to be an enlargement of the latter. Similar

Table 1 Comparison of geometric and syntactic properties of the four centers and the city of Qingdao analyzed in axial model

\begin{tabular}{llllllllllllllll}
\hline $\begin{array}{l}\text { Center/ } \\
\text { Area }\end{array}$ & $\begin{array}{l}\text { Size } \\
\text { (ha) }\end{array}$ & $\begin{array}{l}\text { Axial } \\
\text { No. }\end{array}$ & $\begin{array}{l}\text { Axial } \\
\text { Density }\end{array}$ & $\begin{array}{l}\text { Line } \\
\text { Len }\end{array}$ & $\begin{array}{l}\text { Seg } \\
\text { Len }\end{array}$ & $\begin{array}{l}\text { Seg/Line } \\
\text { Ratio }\end{array}$ & Con & R3 & Rr & Rn & $\begin{array}{l}\text { Con/ } \\
\text { R3 }\end{array}$ & $\begin{array}{l}\text { Con/ } \\
\mathbf{R r}\end{array}$ & $\begin{array}{l}\text { Con/ } \\
\mathbf{R n}\end{array}$ & $\begin{array}{l}\text { R3/ } \\
\mathbf{R r}\end{array}$ & $\begin{array}{l}\text { R3/ } \\
\mathbf{R n}\end{array}$ \\
\hline Zhangshan & 101 & 105 & 1.040 & 269 & 48.8 & 0.187 & 6.076 & 2.383 & 1.422 & 0.965 & 0.721 & 0.567 & 0.615 & 0.864 & 0.824 \\
Taidong & 79 & 71 & 0.899 & 385 & 61.5 & 0.169 & 7.014 & 2.648 & 1.529 & 0.963 & 0.793 & 0.591 & 0.448 & 0.815 & 0.637 \\
Liaoning & 50 & 72 & 1.440 & 248 & 47.2 & 0.220 & 5.806 & 2.338 & 1.347 & 0.855 & 0.665 & 0.515 & 0.417 & 0.803 & 0.539 \\
Tuandao & 78 & 69 & 0.885 & 309 & 53.8 & 0.200 & 6.217 & 2.365 & 1.431 & 0.808 & 0.802 & 0.638 & 0.353 & 0.899 & 0.517 \\
Cen Mean & 77 & 79 & 1.026 & 303 & 53.7 & 0.194 & 6.278 & 2.434 & 1.432 & 0.898 & 0.745 & 0.578 & 0.458 & 0.845 & 0.629 \\
City & 2620 & 2794 & 1.066 & 174 & 53.8 & 0.296 & 3.845 & 1.737 & 1.160 & 0.782 & 0.635 & 0.294 & 0.232 & 0.717 & 0.545 \\
\hline
\end{tabular}

Len length, Seg segment, Con connectivity, $R 3$ radius 3 integration, $R r$ radius-radius integration, $R n$ radius $\mathrm{n}$ integration, Con/Rn $\mathrm{R}^{2}$ correlation of connectivity and $\mathrm{Rn}$ integration 
Table 2 Comparison of syntactic properties of the four centers and the city of Qingdao analyzed in segment model

\begin{tabular}{|c|c|c|c|c|c|c|c|c|c|c|}
\hline $\begin{array}{l}\text { Center/ } \\
\text { Area }\end{array}$ & $\begin{array}{l}\text { Int. } \\
\text { R750m }\end{array}$ & $\begin{array}{l}\text { Int. } \\
\text { R1500m }\end{array}$ & $\begin{array}{l}\text { Int. } \\
\text { R3000m }\end{array}$ & $\begin{array}{l}\text { Int. } \\
\text { Rn }\end{array}$ & $\begin{array}{l}\mathrm{LnCH} \\
\mathrm{R} 500 \mathrm{~m}\end{array}$ & $\begin{array}{l}\mathrm{LnCH} \\
\mathrm{R750m}\end{array}$ & $\begin{array}{l}\text { LnCH } \\
\text { R1500m }\end{array}$ & $\begin{array}{l}\mathrm{LnCH} \\
\mathrm{R} 3000 \mathrm{~m}\end{array}$ & $\begin{array}{l}\mathrm{LnCH} \\
\mathrm{Rn}\end{array}$ & $\begin{array}{l}\text { Metric MD } \\
\text { R1500m }\end{array}$ \\
\hline Zhangshan & 240.4 & 591.7 & 1126.2 & 1735.9 & 6.619 & 7.669 & 9.314 & 10.433 & 10.984 & 944.6 \\
\hline Taidong & 190.9 & 424.7 & 751.2 & 1610.5 & 6.355 & 7.381 & 8.798 & 9.944 & 10.879 & 872.6 \\
\hline Liaoning & 193.8 & 390.1 & 911.4 & 1521.1 & 6.672 & 7.551 & 8.763 & 9.888 & 10.483 & 901.9 \\
\hline Tuandao & 176.2 & 372.6 & 691.9 & 1466.2 & 6.322 & 7.421 & 8.858 & 9.691 & 10.759 & 856.9 \\
\hline Cen Mean & 200.3 & 444.8 & 870.2 & 1583.4 & 6.492 & 7.506 & 8.933 & 9.989 & 10.759 & 856.9 \\
\hline City & 126.2 & 325.5 & 717 & 1427.5 & 5.706 & 6.685 & 8.187 & 9.335 & 9.958 & 956.7 \\
\hline
\end{tabular}

Int. angular integration, $R$ metric radius, $R n$ metric radius $n$, i.e. unlimited metric radius, $C H$ angular choice, $L n C H$ logged angular choice, $M D$ mean distance

observations could be found in other centers, showing that the smaller islands for commercial use are surrounded by the larger blocks for residential use.

The part-whole relationship of the syntactic structure is examined to see if the centers are structured differently from the city in terms of the association between their local and global properties. Results show that the centers on average have a significantly higher value both in terms of intelligibility (measured with the correlation $\mathrm{R}^{2}$ between connectivity and $\mathrm{R}$ integration values) and synergy (measured with the correlation $\mathrm{R}^{2}$ between $\mathrm{R} 3$ integration and $\mathrm{Rn}$ integration values). On the other hand, the correlation value of connectivity and $\mathrm{Rn}$ integration is significantly lower than that of connectivity and R3 integration, indicating that the spatial configuration of these centers focuses more on the local level rather than on the global level. This is markedly pronounced by the Tuandao Center, which has the highest local intelligibility value (correlation $\mathrm{R}^{2}$ between connectivity and R3 integration) at 0.638 , while it is less prominent for the Zhongshan Street Center, which has the highest global intelligibility value at 0.615 . In addition, the four centers have an almost equally strong correlation between R3 integration and radius-radius integration and behave better than the city in this aspect. However, when the correlation between R3 integration and $\mathrm{Rn}$ integration is considered, only the Zhongshang Street Center and the Taidong Center remain to have a higher synergy value than the city on average $\left(R^{2}=0.824\right.$ and 0.637 , respectively). The part-whole relationship analysis suggests that, in addition to the spatial differentiation from other urban areas, these centers also have different ways to embed themselves into their urban context.

\subsection{Retail distribution pattern of urban centers}

Land use pattern in each center is examined with a focus on retail distribution (in terms of the length and continuity of shop frontage along street segment), in order to see if spatial factors could account in certain way for

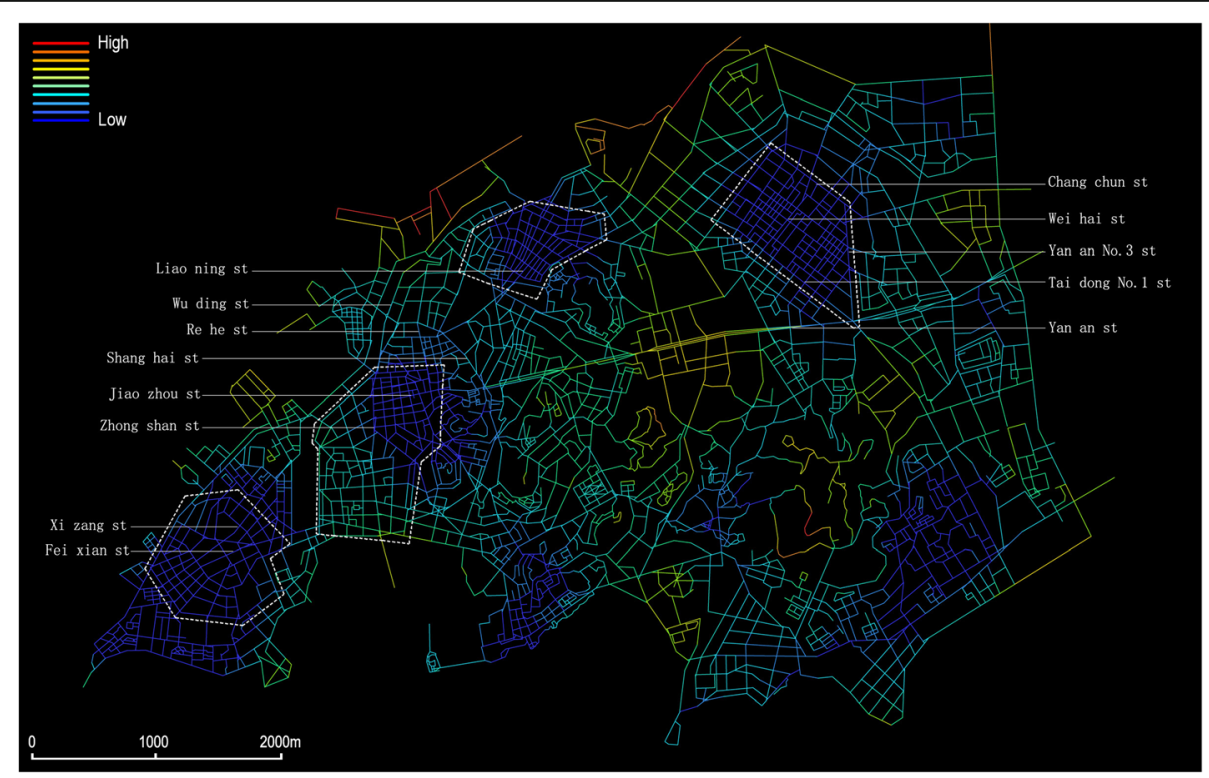

Fig. 9 Metric mean distance at a radius of $1500 \mathrm{~m}$, blue color showing low distance values and highlighting a natural spatial area-isation of distinguishable zones against the centers 
the pattern commonality and difference among individual centers. In general, the distribution of retail shops is influenced by local grid property. They are more likely to locate themselves on street segments with higher local (low radius) integration value to minimize mean trip length within the grids, configurationally and geometrically, and thus take advantage of potential movement that benefits retail function. Most often, but not always, these street segments are constituents of major streets of a center as well as principal integrators of the global structure of the city. Retail function could also develop in other locations with less strong local integration. But this is more likely to happen at locations of street intersections. On the other hand, however, large retail shops, like departmental stores, super markets and specialized shopping centers, tend to locate themselves on principal global integrators, whether at a location of street intersection or segment, and therefore benefit from potential movement from the widest possible urban context (Fig. 10).

In cases of the Zhongshan Street Center and the Taidong Center, whose grid configurations consist of smaller blocks and have both strong edge integration and internal structure, retail function appears to have a higher density of distribution and, generally, develops a convex pattern within the grid structure. In the Zhongshan Street Center, the convex shape of retail distribution is strongly biased towards its northeast part where the local grids are configurationally and geometrically more intensified; whereas in other parts of the center, retail function is distributed in a more or less linear pattern along local integrators leading out of the convex structure. Although retails in the Taidong Center display a convex pattern of distribution, they are distributed quite evenly within the grid structure with no obvious linear extension. For the Liaoning Street Center and the Tuandao Center, the street pattern is more deformed with larger scale of block size, and the syntactic structure is integrated more globally than locally. Whereas retails in these centers are still likely distributed in the grid interior, the intensity of the retail development is significantly lower than the other two centers whose grid structure is integrated more locally than globally. Thus, in the Liaoning Street Center and the Tuandao Center, retail function appears to have a rather uneven development with linear pattern marked by local integrators of the grid.

The different patterns of retail distribution among the four centers suggest that the ways that centers are structured internally and externally in the city have a relationship with the functional differentiation of centers. It seems that in the Zhongshan Street Center and the Taidong center, the strong global integration of an intensified local structure synchronizes a more intensive concentration of retail shops distributed in convex shape, indicative of the city-wide status of these centers. While in the Liaoning Street Center and the Tuandao center, a less locally integrated structure leads to the development of a more linear and less intensified retail distribution, suggesting an identity of local center or subcenter of the city. Thus, the functional differentiation of these centers is not only marked by building size and number of shops that a center may have, but also manifested in the ways that socio-economic activities are structured within a center and related to the city as a whole.

\section{Discussion and conclusions}

This study examines the development of the four centers and sub-centers growing up from settlements or preurban towns that had been built through successive phases of urban growth in Qingdao before the 1950s. A perspective of location morphology history allows these centers to be identified where they are with land use distributions, building typologies and socio-economic concentrations. However, the syntactic analysis enables a deeper understanding of why these centers choose particular locations that distinguish them from their context and evolve spatially and functionally different towards specific directions.

In spite of the rather disperse urban origins and the complex geographic conditions of Qingdao, the syntactic centralities of centers as suggested by space syntax theory are still observed, as indicated by the strong spatial and functional correlates of centers as a result of juxtaposition of different layout morphologies toward the evolving changes of the structure of the city within which a center is embedded (Karimi, 2000). This suggests the emergence of centers is associated with distinctive spatial environment, configurationally and geometrically. The association of centers with a natural spatial "area-isation" of the city into distinguishable zones highlights the presence of metric integration and the centrality process as demonstrated by space syntax studies (Hillier et al., 2007; Park, 2009; Shen et al., 2013; Yang \& Hillier, 2007 \& 2015). The centrality process in Qingdao is observed at both local and global levels. The locally intensified grid structure minimizes mean trip distance within a center and the globally integrated grid structure minimizes mean trip length from other locations into the center, therefore rendering centers with different scales of accessibility that benefit movement engaged activities.

On the other hand, the study reveals that the development of centers in Qingdao appears to have a historical origin, in that the different scales of accessibility associated with the centers are related to both the pre-urban road network of the city, and local grid conditions of 


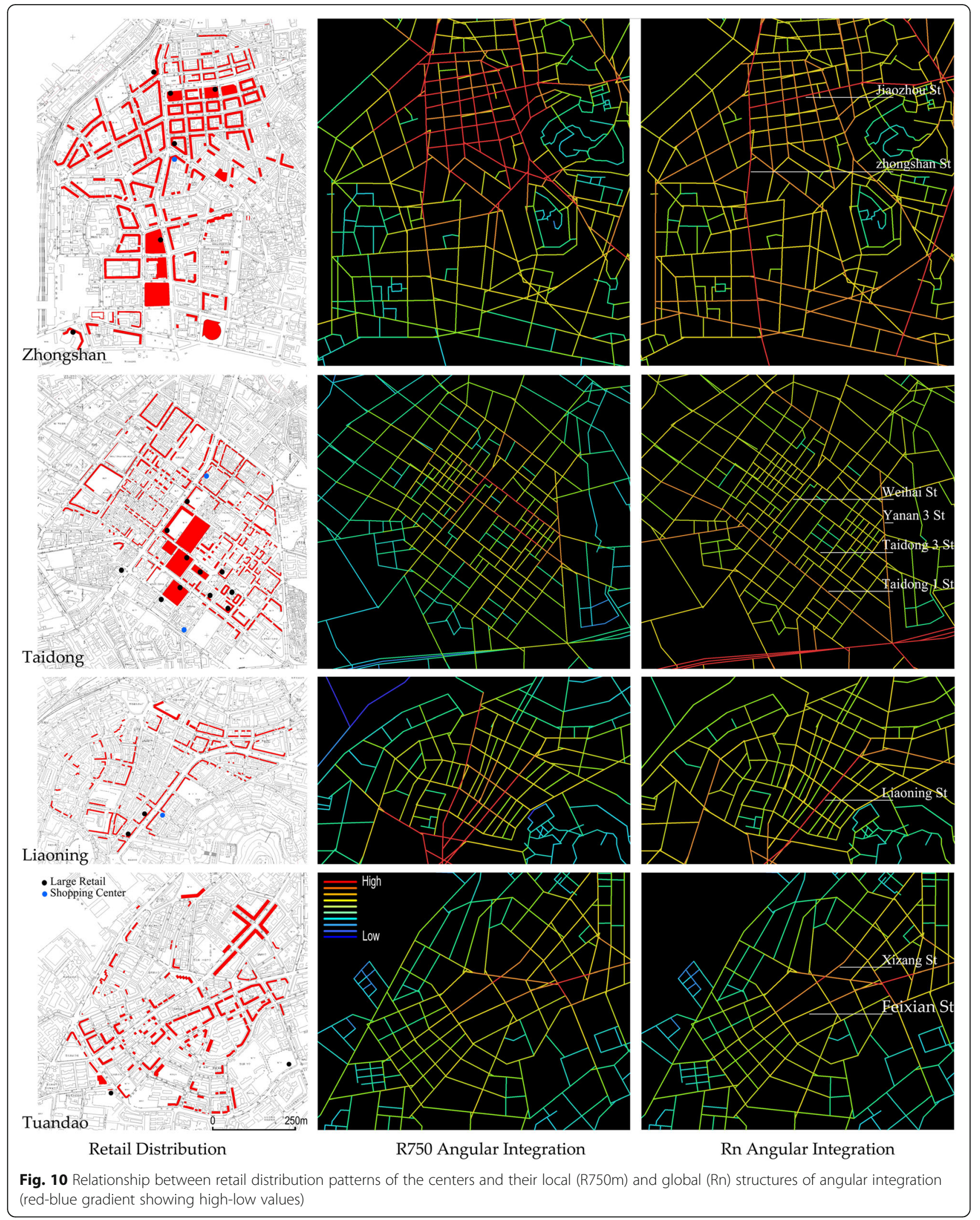


those old settlements from which a center has grown (Griffiths et al., 2010). What is particular for the case of Qingdao is the relationship between the integration structure of the contemporary street system and the preurban road network. In spite of successive phases of urban growth and expansion, old lines of the pre-urban roads have been largely followed by the structure of street system due to physical constraints of the city. Meanwhile, the distinctive local grid conditions of old settlements have been either preserved or maintained. It seems that the overall condition of the city, related to the ways that sub-areas are connected with each other, frames the global structure of the city and renders those old settlements with potentials for movement engaged activities. While the local grid structure set by metric and topo-geometric properties influences the actual concentration pattern of social economic activities and determines the range and strength of a center within the urban context.

The development of centers in Qingdao suggests that the morphological structure of city may be historical in nature, in the sense that old settlements or towns are not simply "absorbed" by urban growth and expansion, but can sustain or even function as a center given proper spatial environment. The study illustrates that urban center is the outcome of the balance between form and function as well as the balance between global and local spatial properties. The old centers can adapt themselves to new functions and maintain a sense of peculiar local identity without significant changes to their urban fabrics. They can function well in modern urban grid by maintaining integration at pedestrian level and closeness to the traffic arteries, as evidenced by the case of Qingdao and other syntactic studies (Feng et al., 2012; Shen et al., 2013; Wang et al., 2017).

\section{Acknowledgments}

We would like to acknowledge Su Shi and Tao Wang at Shenzhen University for preparing the space syntax models and drawings, and Xiaoyang Deng at Qingdao City Planning and Design Institute for his help with getting historical maps used in this study.

\section{Code availability}

The Depthmap software used in the study is an open-source software available at https://github.com/SpaceGroupUCL/depthmapX/releases.

\section{Authors' contributions}

Conceptualization \& Methodology, Wang H.F.; Investigation, Wang H.F. and Rao X.J.; Resources \& Data, Rao. X.J.; Writing, Wang H.F.; Project administration, Rao X.J. The author(s) read and approved the final manuscript.

\section{Funding}

The authors have no relevant financial or non-financial interests to disclose.

\section{Availability of data and materials}

The datasets analysed during the current study are available from the corresponding author on reasonable request.

\section{Declaration}

\section{Competing interests}

The authors declare no conflict of interest.

Received: 20 April 2021 Accepted: 24 August 2021

Published online: 06 September 2021

\section{References}

Al-Sayed, K., Turner, A., Hillier, B., lida, S., \& Penn, A. (2014). Space syntax methodology (4th edition). Bartlett School of Architecture, UCL.

Burger, M., \& Meijers, E. (2012). Form follows function? Linking morphological and functional polycentricity. Urban Studies, 49(5), 1127-1149. https://doi.org/1 $0.1177 / 0042098011407095$

Chiaradia, A., Hillier, B., Schwander, C., \& Wedderburn, M. (2012). Compositional and urban form effects on centers in greater London. Urban Design and Planning, 3, 21-42.

Cutini, V. (2001). Configuration and centrality: Some evidence from two Italian case studies. In Proceedings of the 3th international space syntax symposium, Atlanta, USA.

Dai, X. L., \& Dong, Q. (2005). Centrality process in orthogonal grid - Case study Suzhou. In Proceedings of the 5th international space syntax symposium, Delft, Netherlands.

Digitized Resources of the Library of Christian-Albrechts University Kiel. (2018). Plan von Tsingtau und Umgebung. Retrieved December 1, 2018, from https://dibiki.ub.uni-kiel.de/viewer/limage/PPN688145795/9/-/

Feng, C., Wang, H. F., \& Rao, X. J. (2012). The morphological evolution of Macau. In Proceedings of the 8th international space syntax symposium, Santiago, Chile.

Griffiths, S., Jones, C. E., Vaughan, L., \& Haklay, M. (2010). The persistence of suburban Centres in greater London: Combining Conzenian and space syntax approaches. Urban Morphology, 14, 85-99.

Hillier, B. (1996). Space is the machine: A configurational theory of architecture. Cambridge University Press.

Hillier, B. (1999). Centrality as a process: Accounting for attraction inequalities in grids. Urban Design International, 4(3-4), 107-127. https://doi.org/10.1057/ udi.1999.19

Hillier, B. (2009). Spatial sustainability in cities: Organic patterns and sustainable forms. In Proceedings of the 7th international space syntax symposium, Stockholm, Sweden

Hillier, B. (2016). What are cities for? And how does it relate to their spatial form? Journal of Space Syntax., 6, 199-212.

Hillier, B., \& Hanson, J. (1984). The social logic of space. Cambridge University Press.

Hillier, B., \& lida, S. (2005). Network effects and psychological effects: A theory of urban movement. In A. Cohn \& D. Mark (Eds.), Spatial information theory. COSIT. Lecture Notes in Computer Science (Vol. 3693, pp. 473-490). Springer.

Hillier, B., Penn, A., Hanson, J., Grajewski, T., \& Xu, J. (1993). Natural movement: Or configuration and attraction in urban pedestrian movement. Environment and planning B: planning and design, 20(1), 29-66. https://doi.org/10.1068/b200029

Hillier, B., Turner, A., Yang, T., \& Park, H. T. (2007). Metric and Topo-Geometric Properties of Urban Street Networks: some convergences, divergences and new results. In Proceedings of the 6th International Space Syntax Symposium, Istanbul, Turkey.

Karimi, K. (2000). Urban conservation and spatial transformation: Preserving the fragments or maintaining the spatial spirit. Urban Design International, 5(3-4), 221-231. https://doi.org/10.1057/palgrave.udi.9000012

Li, B. H., \& Li, C. (2005). A study of the history of Qingdao early modern city planning (1891-1949). Urban Planning Forum (in Chinese), 6, 81-86.

Li, D. Q. (2007). Historical study and revelation on the relationship between urban Planning and urban development of Qingdao in modern times. Journal of Chinese Historical Geography (in Chinese), 2, 125-136.

Li, D. Q., \& Zhou, Y. X. (2007). Historical study on the relationship between urban planning and urban development: A case of Qingdao in modern times. New Architecture (in Chinese), 2, 16-22.

Ozbil, A., Peponis, J., \& Stone, B. (2011). Understanding the link between street connectivity, land use and pedestrian flows. Urban Design International, 16(2), 125-141. https://doi.org/10.1057/udi.2011.2

Park, H. T. (2009). Boundary effects on the intelligibility and predictability of spatial systems. In Proceedings of the 7th international space syntax symposium, Stockholm, Sweden. 
Peponis, J., Ross, C., Rashid, M., Kim, S. H., Varela, G., \& Sentosa, L. (1997). The structure of urban space, movement and co-presence. Geoforum, 28(3-4), 341-358. https://doi.org/10.1016/S0016-7185(97)00016-X

Porta, S., Latora, V., Wang, F., Rueda, S., Strano, E., Scellato, S., \& Latora, A. (2012). Street centrality and the location of economic activities in Barcelona. Urban Studies, 49(7), 1471-1488. https://doi.org/10.1177/0042098011422570

Porta, S., Strano, E., lacoviello, V., Messora, R., Latora, V., Cardillo, A., \& Scellato, S. (2009). Street centrality and densities of retail and services in Bologna, Italy. Environment and Planning B: Planning and Design, 36(3), 450-465. https://doi. org/10.1068/b34098

Qingdao Municipal Archives (Ed.). (2002). Historical maps of Qingdao (in Chinese). Shandong Maps Press.

Scoppa, M. D., \& Peponis, J. (2015). Distributed attraction: The effects of street network connectivity upon the distribution of retail frontage in the city of Buenos Aires. Environment and Planning B: Planning and Design, 42(2), 354378. https://doi.org/10.1068/b130051p

Shanghai Tongji Urban Planning and Design Institute; Qingdao City Planning and Design Institute. (2014). Monographic study on the conservation planning of Qingdao historical and cultural city (in Chinese). Internal Report.

Shen, Y., Karimi, K., \& Xia, Q. (2013). Morphological transformation of historical centres in Tianjin. In Proceedings of the th international space syntax symposium, Seoul, South Korea.

Sheng, Q., \& Zhou, C. (2018). Function follows space: Urban centers under multiple scale network structure (in Chinese). The Architect, 6, 60-67.

Siksna, A. (1997). The effects of block size and form in north American and Australian City Centres. Urban Morphology, 1, 19-33.

Tallon, A. (2013). Urban regeneration in the UK. Routledge. https://doi.org/10.4324/ 9780203802847

Turner, A. (2004). Depthmap 4-A Researcher's handbook. Bartlett School of Graduate Studies, UCL Online publication. Accessed 1 Dec 2020, from http:// discovery.ucl.ac.uk/2651/1/2651.pdf

Turner, A., Penn, A., \& Hillier, B. (2005). An algorithmic definition of the axial map. Environment and Planning B: Planning and Design, 32(3), 425-444. https://doi. org/10.1068/b31097

Van Nes, A. (2021). Spatial Configurations and Walkability Potentials. Measuring Urban Compactness with Space Syntax. Sustainability, 13, 5785. https://doi. org/10.3390/su13115785

Wang, H. F., Wang, J. Q., \& Shi, S. (2017). The changes of downtown Zhongshan city in modern times and functional differentiation of historical streets (in Chinese). South Architecture, 5, 68-74.

Wang, J. W., Mao, Q. Z., \& Dang, A. R. (2008). An evolution model of Beijing - A discussion on the evolution of urban spatial and functional patterns based on space syntax (in Chinese). Urban Planning Forum, 3, 82-88.

Warner, T. (2011). City Planning and construction of modern Qingdao (in Chinese). Southeast University Press.

Yamu, C., \& Frankhauser, P. (2015). Spatial accessibility to amenities, natural areas and urban green spaces: Using a multiscale, multifractal simulation model for managing urban sprawl. Environment and planning B: planning and design, 42, 1054-1078.

Yamu, C., van Nes, A., \& Garau, C. (2021). Bill Hillier's legacy: Space syntax—A synopsis of basic concepts, measures, and empirical application. Sustainability, 13(6), 3394. https://doi.org/10.3390/su13063394

Yang, T., \& Hillier, B. (2007). The fuzzy boundary: The spatial definition of urban areas. In Proceedings of the 6th international space syntax symposium, Istanbul, Turkey.

Yang, T., \& Hillier, B. (2015). Spatial discontinuity in the multi-scaled area structures of the central historical districts of London and Beijing. In Proceedings of the 10th international space syntax symposium, London, UK.

\section{Publisher's Note}

Springer Nature remains neutral with regard to jurisdictional claims in published maps and institutional affiliations. 